the inhabitants of this country are protected from small-pox by vaccination during infancy, and thus possibly may also be protected from rinderpest.

These considerations may not be sufficient to establish absolutely the pathological identity of rinderpest and variola, but they unquestionably point to a very close analogy between them. The object of this communication, however, is not to insist that the two diseases are pathological equivalents, but to enlist the assistance of the medical profession in clearing up the matter. The mode of procedure is obvious and sufficiently simple. It is to produce cow-pox in cattle by inoculating them on the one hand with vaccine lymph, and on the other with the matter of human variola, and afterwards to ascertain if they be proof against the prevalent plague, or if the course of the rinderpest be thereby modified. If the results of these experiments turn out as I think there is reason to anticipate, the vexed question of the pathological nature of rinderpest will be finally settled, and mankind will be furnished with a certain remedy for arresting its ravages.

Wimpole-strect, December 25th, 1865.

\section{ON PROGRESSTVE LOCOMOTOR ATAXY, OR WASTING OF THE POSTERIOR COLUMNS OF THE SPINAL CORD.*}

Br JULIUS ALTHAUS, M.D., M.R.C.P.,

PHYSICIAN TO TITE ROYAL INTIRMARY FOR DISEASES OF THE CHEST, CITT-ROAD.

The disease to which I purpose to draw attention is not a new one, for it was more than thirty years ago described by various authors as tabes dorsalis, and more recently, chiefly by French physicians, as progressive locomotor ataxy. Yet the nature of the complaint, and the connexion which exists between the symptoms manifested during life and the structural changes found after death, have, until quite recently, been misunderstood, and $I$ therefore offer no further apology for bringing this important subject under notice. Before, however, proceeding to a description of the disease as it is now known, I will say a few words about its name and history, showing the steps by which we have gradually attained to that knowledge of its character which we possess at present.

Tabes dorsalis is first spoken of in the works of Hippocrates, and was by the father of medical literature believed to arise from excesses in sexual intercourse, the chief symptoms of the disease being spermatorrhcea, marasmus, and hectic fever. This meaning of the term, however, has gradually changed, and those anthors who wrote on tabes in the first decennia of this century understood by it atrophy of the posterior portion of the spinal cord, brought on, not merely by sexual exhaustion, but also by exposure to wet, rheumatism, gout, and other causes, the chief symptom being a peculiar form of paraplegia. The disorder was chiefly investigated by English and German physicians, such as Abercrombie, Hufeland, Steinthal, Rom. berg, and others. Their descriptions, although in some instances most eloquent, were however, to a certain extent, wanting in accuracy, inasmuch as several different affections of the cord were comprehended under the name of tabes, and a clear distinction was not drawn between tabes and paraplegia. It was only after a more careful clinical study of the symptoms had been made, and after pathological anatomy, aided by the microscope, had stepped in, that a peculiar disease of itself, and one characterized by uniform structural lesions, could take its place in our nosological system. The chief credit of the anatomical investigations is due to Professors Virchow, Tiurck, Rokitansky, and Leyden, and in this country to Dr. Gull and Mr. Lockhart Clarke, who have shown that, in well-marked cases of tabes, an actual waste of nerve-fibres of the posterior columns of the spinal cord takes place, together with the formation of amyloid corpuscles, and considerable proliferation of connective tissue.
The first who drew a distinction between this disease and paralysis was Dr. Todd. He said, in an article on the nervous system in his Cyclopredia, that two kinds of paralysis might be noticed in the lower extremities : the one consisting simply in the impairment or loss of voluntary motion; the other distinguished by a diminution or total absence of the power of coordinating movements. In the latter form, while considerable muscular power remained, the patient found great difficulty in walking, and his gait was so tottering and uncertain that his centre of gravity was easily displaced. In these few words we have a good description of the symptom of ataxy, upon which lately so much stress has been laid by French physicians. The term "ataxy" is as old as that of "tabes," for it also originated with Hippocrates; and it has likewise entirely changed its meaning in the course of time. Some authors have applied it to chorea, others to fevers, others to various nervous disorders. At present, however, we understand by ataxy, not a disease of itself, but merely a symptom to which various disorders may give rise, and which essentially consists of a want of co-ordination of voluntary movements, and a tendency on the part of the pationt to lose his balance, but without actual loss of power, and apart from tremor, chorea, and paralysis. This symptom may be observed in disease of the cerebellum, and in poisoning by alcohol, lead, and mercury; but it is more especially connected with that disease which has been long familiar to us as tabes. The best clinical study of this symptom we owe to M. Duchenne de Boulogne, who from 1858 up to this time has published a number of memoirs, in which he described what he thought to be an entirely new disease, which he called "progressive locomotor ataxy" and which he believed to be a functional disorder of the cerebellum. His apparent discovery was hailed as a real one in France, and Professor Trousseau actually proposed to call the new stranger "Duchenne's disease;" but, on looking more closely into the matter, we find that Duchenne's description is altogether applicable to our old friend, tabes. I have not the slightest hesitation in acknowledging the great ability and originality of M. Duchenne's researches, which were perhaps more strikingly displayed in this case just on account of his being unacquainted with the previous literature on the subject; yet, if I thought it desirable to attach a proper name to this affection, I should prefer calling it "Todd's disease," as Todd hirst drew the distinction between ataxy and paralysis eleven years previous to Duchenne. But the best plan is, perhaps, merely to drop the term "tabes," as being too vague, and to call the disease under consideration "progressive locomotor ataxy, or wasting of the posterior columns of the spinal cord."

The following details of a case of this affection which I have had under my observation for about five years are well suited to illustrate the symptoms and progress of the disease:-

R. B- a commercial traveller, aged thirty-seven, a tall and rather spare man, with a sallow complexion, first consulted me in February, 1860, when he gave me the following history. His mother had always been healthy, but his father had for the greater part of his life suffered from epilepsy, and died in a fit. The patient was brought up to the law; but in consequence of a disappointment he left that profession, and enlisted as a soldier. He served in Australia and Canada, and during that time suffered much from rheumatism. He never exceeded in drinking, but occasionally in sexual intercourse. He twice had gonorrhoea, but no syphilis. He suffered for a long time from hæmorrhoids, for which, in 1855, he underwent the operation by ligature, and he ascribed the commencement of his present illness to that operation, saying that he never felt quite the same man after the hæmorrhoidal flow had ceased. He left the army in 1856, and married. He is now father of a healthy child. For the last eighteen months he has been a commercial traveller, and as such he is always on the move, and frequently exposed to cold, damp, and great fatigues. In January, 1857, he first noticed that his sight became weak, and he had some difficulty in writing and reading small print. Soon after he felt pains of a peculiar character, which he described as electric shocks through the legs, and as if the muscles were being rent asunder. These shocks came every two or three minutes. He underwent treatment by liniments and other external applications, but without relief. His gait now became tottering, and he had considerable diffi. culty in walking. He never goes out without a stick, and sometimes he is obliged to use two. In summer 1859 he consulted the late Dr. Todd, who told him that his case was incurable, and that he would have to be on the sofa for the rest of his life. He prescribed strychnine and iron, and after having taken it for some time the patient felt rather stronger, but there was no improvement in the special symptoms of the disease. 
Present state-February 14th, 1860 : The patient's intellect, memory, and speech are quite mormal. He does not suffer from headache, gicldiness, strabismus, or ptosis. Both pupils are enlarged, the left more so than the right. He complains of weak sight, and the ophthalmoscopic cxamination shows the arteries of the optic nerve smaller than usnal. His senses of hearing, smell, and taste are natural. Respiration and heart-sounds normal; pulse at the wrist ratler feeble, but quite regular. His digestion is tolerably good. Tongue clean, appetite satisfactory, but bowels rather costive. He complain of a sensation as if a net were tightly drawn round the abdomen. He is occasionally troubled in passing the urine, but there is no stricture. The urine is of 1030 specific gravity, and contains a sediment of urates, but no excess of phosphates, and no albumen or sugar. The sexual power has not notably diminished of late. On examination of the back by pressure, percussion, galvanism, and hot sponges, no place can be discovered which is particularly sensitive. The patient complains of numbness in the hands, more especially in the third and fourth fingers of the left hand. He can distinguish heat and cold, and feels the prick of a pin and pressure distinctly; yet the esthesiometer shows a considerable diminution of tactile sensibility in the fingers. The upper extremities are pretty well nourished, and the muscles answor woll to a galvanic current of moderate power. He can bend and stretch the arms with force, but he finds it difficult to button his shirt and to feed himself. The lower extremities are more affected than the upper ones. The patient has had sensations of "pins and needles" in the feet, but these have for some time past given place to numbness. He says that in walking he has a sensation as if he trod on cotton or springs, and when going upstairs he feels as if the steps rose under his feet. He must continually look at his limbs in order not to lose his balance, and can scarcely walk at all in the dark. If told to shut the eyes or stand with both feet together, he begins to stagrer. In walking, he throws the legs forwards with a jerking motion; and, as he cannot measure his distance from the ground, he puts his foot down with great force. If lying down, he can bend and stretch the legs with considerable power, but he seems to exaggerate evary movement, all muscular contractions being, not slow and equable, but violent, sudden, and jerking.

I ordered the patient thirty minims of the syrup of iodide of iron three times a day, sulphur baths twice a week, and a pill of aloes and myrh at bedtime. After having used these remedies for about a month, there was a marked improvement in erery respect. The pains were nearly gone, the sight was rather better, the walking decidedly steadier and less fatiguing, and the feeling of numbness slighter. He went on favourably until March, 1801 , when, having a long and very laborious journey to perform, he returned considerably worse, and from that time the disease gradually gained upon him, in spite of all treatment. In 1863 he had a course of nitrate of silver, but the affection was then evidently too far advanced for any medication to do good. The sight got rapidly worse, and he became at last completely amaurotic. 'The sensation in the lower extremities was also entirely lost. The patient was now confined to his room, and during the last six months of his life he never left his bed. His intellect remained unimpaired to the last, and his disposition was always cheerful. He died in January, 1865, of a sharp attack of bronchitis.

[The author then described in detail the anatomical changes which are found in patients who have succumbed to this disease; after which he proceeded to an elaborate analysis of the special symptoms, laying chief stress on the affection of the cerebral nerves and the pains in the first stage, and on the symptoms of ataxy and the loss of the different kinds of sensibility in the second stage of the disorder. The causes generating ataxy were then mentioned, and the diagnosis was fully gone into. He then continued :-

The prognosis is not favourable, for up to the present time not a single case is on record in which perfect recovery has ensued. Indeed, as late as 18501, Rombers wrote that there was no hope for patients of this class, that a fatal issue was inevitable, and that it was but common humanity to inform them that therapeutic interference could only injure. This sad confession of impotence need no longer be made, and we may certainly congratulate ourselves on having far more control over the disease than we had formerly. Moreover, its progress is sellom rapid, although acute intercurrent disorders, such as erysipelas, bronchitis, and pneumonia, are grave complications which may carry the patient off suddenly. Much must depend upon the period at which the case comes under treatment. If all the symptoms of the disorder are fully developed, the hope of a cure may be slight, although even then much may be done to alleviate the patient's suffering. The case is different if the patient presents himself in an early stage of the disorder. The fact that the cerebral nerves, with the exception of the optic, generally recover from their affec. tions in the course of the disease, goes far to prove that previous to the structural changes in the cord there is a functional stage, in which much may be done by medicines. Moreover, we must bear in mind that Messrs. Charcot and Vulpian have found nervous fibres in the process of reparation in the cord of a man who had died from ataxy; and that therefore even at a later time we must not give up hope altogether, especially if the patient is placed in favourable circumstances.

I now come to the treatment of ataxy, and will first say a few words about diet and regimen. This must depend a good deal upon the condition in which the patient is at the time he comes under treatment. If he is in a weakly state, plain and nourishine diet, with iron, quinine, and cod-liver oil, should be prescribed. I have never seen a case in which lowering did any good. Hippocrates has recommended milk diet in erotic tabes, and Fisenmann speaks highly of the same in progressive ataxy. I have often given milk-and-brandy, two and and even three times a rlay, with decided benefit to the general health; but have never found it expedient to insist on an exclusive milk diet. Exercise should be very moderate; and for those who have undergone great fatigue, rest is most beneficial.

Counter-irritants to the spine have been used by many physicians, but, as a rule, the benefit obtained has not been proportionate to the sufferings irflicted by their application. The moxa, the hot iron, issucs, blisters, and leeches have been employed. I give the preference over all of these to the continuous galvanic current, applied to the lower and middle portion of the spine. It has in several cases seemed to me of decided benefit in lessening the pains, and also the disagreeable feeling of constriction which is often felt at the abdomen and the chest. The action of this agent is as rapid as that of the iron; its application entails far less trouble and suffering than this latter; and its efficacy is superior to that of issues, blisters, and leeches. Dry cupping on both sides of the spine is also useful.

Iodide of potassium has been recommended by Duchenne and others; but no cases have been published in which this remedy has proved successful. On the contrary, several are on record in wlich it seemed to accelerate the progress of the disease. I have given it in two cases, but without any effect, and am certainly not in favour of its alministration. Iodide and bromide of iron are useful, but do not effect a cure. Mineral waters have been very frequently employed, both externally and internally; and it seems that for a time they do good. Amongst the French soas, Bareges is the one most recommended; amongst the German waters, Marienbad and Wiesbaden have a special reputation; while chalybeates and indifferent thermal springs, which often prove useful in certain forms of paralysis, have entirely failed in ataxy. On the whole, I should be arerse to sending atactic patients on a journey to some distant spa, as rest at home, with certain remedies to be mentioned hereafter, is more beneficial than all the mineral waters in the world. If, however, there should be costiveness and abdominal plethora, Carlsbad, Marienbad, or. Kissingen water may be drunk at home with benefit. Sulphur baths may also be taken at home; and I think highly of them. I have never employed them alone; but they certainly seemed, in conjunction with other remedies, to do much in relieving the pains and diminishing the numbness. The patients feel more brisk and supple after the baths, and are almost always desirous of repeating them as often as possible. A sulphur bath may be prepared by dissolving from three to six ounces of the sulphuret of potassium in two pints of warm water, and adding this to the bath. Vapour baths and Turkish baths should be avoided.

Nux vomica and strychnine have frequently been used, but generally seemed to do harm. Duchenne recommends faradization, and the late Professor Remak, of Berlin, praised galvanization as a curative agent. From faradization I have never seen any benefit; calvanization has proved useful at my hands not only in the pain and fecling of constriction, but also in the affections of cerebral nerves which are so frequent in the commencement of ataxy; on the other hand, it his been powerless against the disease itself, more especially against the symptom of ataxy.

Amongst the other remedies which have been used in this affection without much result, I will mention opiam, bromide of potassium, secale cornutum, essence of turpentine, and arsenic. The only remedy which seems as yet to have some 
good, in a very large proportion of cases, is the nitrate of silver, given in doses of one-tenth to a half grain, two or three times a day. Professor Wunderlich, of Ieipzig, was the first who employed silver in seven cases of this discase, in none of which, it is true, he obtained an actual cure, but in most of them considerable improvement. In 1862, Messrs. Charcot and Vulpian, in France, took up Wunderlich's idea, and used the nitrate in five other cases, and in each of them there was much amendment. Since then this remedy has been employed in most cases of ataxy, and with somewhat variable success. In some it has so disagreed with the patients that it was necessary to discontinue its use; in others it had little or no effect; while in the majority of cases the remedy has proved, if not curative, at least very useful, and it is the one upon which most reliance can be placed in the treatment of this disease. I am in the habit of giving the silver combined with the hypophosphite of soda, and it seems to do far more in this combination than either of these remedies singly. I have, indeed, now a case of ataxy under my care in which the improvement has, for the last six months, been so consilerable under this medication that I am hopeful of a cure. Certain precautions should, however, be taken in administering the nitrate. I generally employ it for four or six weeks consecutively, and then discontinue it for a fortnight or three weeks, giving in the meantime a slightly aperient mineral water. After this the use of the remedy may be safely recommenced, and continued for a month or so. The gums must be inspected from time to time, as the peculiar coloration which silver produces in the long run first appears in the mucous membrane, and only afterwards in the skin. With the precautions mentioned, however, no disfigurement of the patient need be feared. I have never gone beyond the dose of half a grain, and perhaps this is another reason why in my cases the remedy has been borme without any inconvenience. I should, however, not recommend all cases of ataxy to be treated alike; in this affection we must, as in every other, study each individual case by itself, and advise for it what seems, under the special circumstances, most likely to do good. Thus hysterical or hypochondriacal patients in whom ataxy may supervene, will require a different treatment from plethoric persons, or sich as have long suffered from rheumatism, or have been subject to privations and anxiety. Much is, therefore, left to the tact and discrimination which, together with knowledge, should, in all cases brought before him, guide the doings of the physician.

\section{NOTES OF PRACTICE AT THE WEST LONDON MOSPITAL.}

BY G. GODDARD ROGERS, M.D., PHYSICEAN TO TFE TOSPITIL.

Some few months since I gave an account in The LANCEr of the success attending the administration of bromide of potassium in certain forms of epilepsy. In doing this I made frequent reference to an able article from the pen of Dr. M'Donnell, which appeared in the Oublin Quarterly Journal for February, 1864 ; and $I$ hoped ere this Dr. M'Donnell would have made good his promise, and given to the profession his further observations on the use of the above-named drug. I much regret that my suggestion was not carried out by the medical staff of any metropolitan hospital. It was, that for a period of three months fair trial should be given to the bromide of potassium in cases of epilepsy characterized by histories similar to those I related. I carefully avoided lauding the remedy as applicable to all and every form of epileptic convulsion; but from what I had seen of its action, I thought it well adapted to cases where uterine derangement might be looked upon as the prime cause of the cerebro-spinal irritation. This I understand to have been the view originally taken by Sir Charles Locock, whose paper I quoted. Further experience of the effects of the bromide has strengthened my idea of its efficacy, and in addition I can record my mite of testimony to its non-hindrance of the genital functions. The portions of THE LANCET devoted to correspondence teemed with anxious inquiries on this head. One would have thought that a valuable remedial agent was about to be tabooed lest the next British census shouht lack its column of increased population. Neither when administered to epileptic males or females as a curative agent, nor to either sex in largish doses merely by way of trial, have very careful inquiries elicited accounts of diminished sexual power. I further ventured to affirm that where the system had been debilitated by the nauseous practice of masturbation, and epilepsy was of frequent occurrence, the good effects of the drug were manifested in a high degree. On this point also I am increasingly confident; but, of course, unless moral agencies can be brought to bear on the patient, all treatment is useless. I have now under my care a young man who formerly had weekly, and not unfrequently daily, epileptic seizures. He is now in the fifcy-fourth week of complete exemption from the attacks, and I shall continue to give him the bromide for some months longer. He has gained flesh, and is able to do a long day's work, and his general appearance is much improved. This leads me to remark, that in numerous cases $I$ have watched. the effects of the drug upon the external tegumentary structures, and have found that the complexion loses its sallowness, or, where naturally inclined to be ruddy, the florid tint is heightened. The eyes become brighter, and the skin generally assumes a more healthy hue.* In prolonged small doses I think I have seen benefit to children affected with chorea, but further experience is required on this head. One very commonly hears it said, "Oh! as to bromide of potassium, don't trouble to get that for your patient; the iodide will do just as well." Now 1 do not think so, nor do I believe that the same vigour is sustained when a lengthened course of the latter medicine is prescribed. I remember making a note of a remark in this journal which I cannot now lay my hand upen. It was to the effect that the Kreatznach waters were unjustly accused of exercising a lovering intluence; and the writer called this a mere random assertion, from a supposed analogy between bromine and iodine.

In two epileptic patients (one of them the case above named) who have been taking the bromide, in doses of a drachm daily, with great benefit, the intermission of the medicme caused. headache and nansea, and a feeling of fulness in the fauces, the tongue also "feeling too large for the mouth." How far these may have been mere nerrous sensations, arising from the idea that a fit must occur because they had no medicine, I cannot say. Probably mental influences had much to do with the matter. It is curious, however, that the same uneasy feelings should be spoken to by both patients, and that in both the resumption of the medicine has caused them to disappear.

The black oxide of manganese is used at the West London Hospital in some forms of dyspepsia, in accordance with the suggestions of Dr. Leared; but not to such an extent as I could wish. Not very long ago, by permission of Dr. Leared, I gave in the pages of THE LANCET some illustrations of its beneficial action. The chief hindrance to its larger administration is the reluctance of the patients themselves to take it. However carefully suspended by tragacanth mucilage, it has an unpleasant grittiness. The wafer-paper might be used perhaps to envelop it when prescribed for private patients. If the palate can tolerate the mixture, and it is regularly taken before a meal, the pain following the subsequent ingestion of food is very much allayed-more so than by bismuth. After the meal the sulphite of soda in small doses greatly adds to the comfort of the dyspeptic person, either of itself allaying the tendency to eructation, and diminishing a sense of fulness so often complained of, or directly aiding the oxide in keeping up a placid condition of the lining membrane during the action of the gastric fluid.

A case illustrative of one of the Protean manifestations of pneumonia occurred lately in a man who had always enjoyed good health previously. He was lifting a ladder the evening before his admission, when, to use his own words, he "found something give way at the pit of the stomach." He went home to bed and got some sleep, but soon woke up screaming with pain across the chest. He was brought to the hospital breath. ing with difficulty, with a flushed face and frequent pulse, and "doubled up" with pain over the inferior cardiac region. Warm fomentations were applied and opiates given, but the pain lost none of its intensity. Auscultation and percussion failed to detect anything wrong, and so we were left in doubt as to the nature of the case for some hours. It seemed likely to prove diaphragmatic pleurisy, but in the evening, when the pain had lessened, very careful examination detected a small extent of fine crepitation just under the spine of the left scapula. Antimony was given, with salines and ammonia, and a blister placed over the back of the lung. The extent of crepitation never increased, and the dulness on percussion was limited to the one infrascapular spot. It was not until the fourth day that any rust-coloured sputa made their appearance. Had this man been treated simply on his own state* Dr. Gibb has noticed much the same effects from bromide of ammonium. 